\title{
RESEARCH
}

Open Access

\section{Breastfeeding technique and associated factors among lactating mothers visiting Gondar town health facilities, Northwest Ethiopia: observational method}

\author{
Boko Loka Safayi ${ }^{1}$, Nega Tezera Assimamaw ${ }^{2}$ and Destaye Guadie Kassie ${ }^{2^{*}}$ (D)
}

\begin{abstract}
Background: The breastfeeding technique is explained positioning, attachment, and suckling during breastfeeding. Ineffective breast feeding technique is one of the factors leading to premature discontinuation of breastfeeding and malnutrition. There is a limited study on the assessments of BFT and associated factors among lactating mothers in the study area. Therefore, the study aimed to assess breastfeeding technique and the associated factors among lactating mothers visiting Gondar town health facilities, Northwest Ethiopia.

Methods: An institution-based cross-sectional study was conducted from February 20 to March 20, 2020. An observational checklist and structured interviewer-administered questionnaire were applied to collect the data. The data were entered into Epi-Data 4.6 version and transferred to analyzed using SPSS version 20. Bi-variable and multivariable logistic regressions were performed to identify the association. The strength of association was identified using odds ratio with a 95\% confidence interval (), and a p-value of 0.05 was declare as statistically significant.

Results: The proportion of effective BFT was 48\% (95\%, Cl: 43.0-53.0\%). The likelihood of applying proper BFT among age group of $18-20$ years was $70 \%$ lower than ( $A O R=0.3 ; 95 \% \mathrm{Cl}: 0.11-0.83$ ) age group $>30$ years. The odds of effective BFT in primipara mothers were $49 \%$ ( $A O R=0.51 ; 95 \% \mathrm{Cl}: 0.32-0.82$ ) lower compared to multiparous mothers. Likewise, the provability of effective BFT was 55\% (AOR $=0.45 ; 95 \% \mathrm{Cl}$ : 0.29-0.70) times lower in women who had no counseling immediately after delivery compared to their counterparts. Moreover, effective breast feeding technique mothers who have breast problem was 78\% lower than ( $\mathrm{OOR}=0.22 ; 95 \% \mathrm{Cl}: 0.07-0.68$ ) mothers who have no breast problem. And mothers who had counselling of BFT during ANC follow up was 55\% $(\mathrm{AOR}=0.45 ; 95 \% \mathrm{Cl}: 0.29,0.70)$ lower than mothers who had no counseling.
\end{abstract}

\footnotetext{
* Correspondence: dstgd32@gmail.com; destye.guadie@uog.edu.et;

destaye.guadie@uog.edu.et; http://www.uog.edu.et

${ }^{2}$ Department of Pediatrics and Child Health Nursing, College of Medicine

and Health Sciences, School of Nursing, University of Gondar, P.O .Box:196,

Gondar, Ethiopia
}

Full list of author information is available at the end of the article

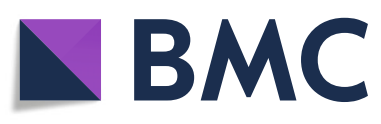

(c) The Author(s). 2021 Open Access This article is licensed under a Creative Commons Attribution 4.0 International License, which permits use, sharing, adaptation, distribution and reproduction in any medium or format, as long as you give appropriate credit to the original author(s) and the source, provide a link to the Creative Commons licence, and indicate if changes were made. The images or other third party material in this article are included in the article's Creative Commons licence, unless indicated otherwise in a credit line to the material. If material is not included in the article's Creative Commons licence and your intended use is not permitted by statutory regulation or exceeds the permitted use, you will need to obtain permission directly from the copyright holder. To view a copy of this licence, visit http://creativecommons.org/licenses/by/4.0/ The Creative Commons Public Domain Dedication waiver (http://creativecommons.org/publicdomain/zero/1.0/) applies to the data made available in this article, unless otherwise stated in a credit line to the data. 
Conclusion: Just under half of the women in the study area applied proper breast feeding technique Younger and primipara mothers poorly performed to effective BFT. But women having counseling during antenatal care followup and immediately after delivery and not having breast problems applied BFT effectively. Hence, special emphasis have to give for younger and primipara mothers. Besides, educate the mother for preventing breast problems and working on enhancing counseling at postnatal clinic.

Keywords: Breastfeeding technique, Lactating mothers, Health facilities, Northwest Ethiopia

\section{Background}

Breastfeeding technique is explained as the mother's and baby's positioning, baby's attachment to the breast, and suckling during breastfeeding, which are very important for effective breastfeeding [1-3]. Appropriate early childhood care and application of effective breastfeeding techniques during infancy are the key to optimum development, health, and survival [4-6]. The World Health Organization (WHO) has recommended to utilize the appropriate breastfeeding techniques that helps to promotes exclusive breastfeeding, due to this reason the baby can get the expected amount of energy and adequate nutrients. In addition, breast feeding is important for both the mothers and infants health with protecting against different acute and chronic disorders [7, 8].

Ineffective BFT is one of the main factors leading to non-EBF and premature discontinuation of breastfeeding [9]. Several evidences revealed that $58 \%$ of mothers with poor BFT cease breastfeeding earlier and interferes with EBF; which ultimately result in a serious of acute infectious diseases like diarrhea, acute respiratory infections, and chronic diseases; such as diabetes, a reduced mental ability, and perhaps an increased risk of epileptic disorders during childhood [6, 8, 10-13].

Other than the afore mentioned problems, poor BFT has profound impact on infant's breast milk intake [9], which leads to the different forms of under nutrition, including macro and micronutrient deficiencies [14]. According to the United Nations, Children's Emergency Fund (UNICEF), WHO, and World Bank joint child malnutrition estimated; inadequate food and breast milk intake are the primary and immediate causes of infant and young child under nutrition. More than half of the deaths of under-five children are due to malnutrition that the most public health problems in developing countries like Ethiopia [15]. Consistent adhering of WHO BFT helps the mother for preventing breast conditions like cracked, sore nipples and other risks [16].

Multiple research reports showed regarding to factors affect the effective BFT are young mothers, primiparity, illiterate mother, unemployed mother, breast diseases, previous breastfeeding experience, Antenatal Care (ANC) and Postnatal Care (PNC) counseling. Moreover infant factors that affect the Effective BFT includes gestational age, the current age of the infant, and bottle feeding $[2,10,14,17,18]$.

The Baby-Friendly Hospital Initiative and WHO designed the counseling, teaching, and demonstration of the correct BFT for the mothers during ANC, PNC, and for all mothers with sick young infant according to the Integrated Management of Neonate and Childhood Illness (IMNCI) guidelines [1, 16, 19-21]. Ethiopia has also adopted WHO IMNCI guidelines, which contain breastfeeding technique assessment components for sick young infants [21]. More recently, in 2019, Ethiopia included ineffective breastfeeding technique as a diagnostic criterion of severe acute malnutrition for infants less than 6 months in the national guideline for the management of acute malnutrition [22].

Despite these, the reduction of infant and preventable under-five mortality is still the main focus of several national and international health organizations. For instance, the Ethiopian government has targeted end childhood under nutrition by 2030, with a commitment to the 'Seqota' Declaration. One way to achieve the aforementioned aimed to promote effective breastfeeding during infancy and early childhood. This study can demonstrate the magnitude and factors contributing to effective BFT which helps to attain the national goal. Though there is a study conducted at' Dire Dawa city, Ormiya region, Ethiopia', the study failed to consider the suckling technique and were not applied an observational data collection technique. Therefore, this study aimed towards assessing BFT and associated factors among lactating mothers in Gondar town, Northwest Ethiopia. By doing this, it would be helpful for community, health care providers as a body of knowledge, programmers, and policy makers in designing strategies for the enhancement of effective breastfeeding in both the study area and similar settings.

\section{Methods}

\section{Study design and setting}

An institution based cross-sectional study was conducted at public health facilities in the Gondar town from February 20 to March 20, 2020. Gondar town is founding in the central Gondar zone, Amhara regional state; north of Lake Tana and southwest of the Simien Mountains. It is far from a distance of $727 \mathrm{~km}$ from 
Addis Ababa, the capital city of Ethiopia. There are one comprehensive specialized hospital and eight health centers which gives services for more than 5000,000 people. According to the Gondar town health office, 652,940 patients visit all the nine governmental health facilities in the town per year, of whom 21,527 are children less than 5 years of age [23]. Each facility's provided vaccination according to the EPI (Expanded Program for Immunization) schedule for children under 2 years with the monthly flow rates 68 up to 632 .

\section{Participants of the study}

All lactating mothers with their infant (mother-infant dyad) visiting the governmental health facilities of Gondar town were the source population. Lactating mothers who came to the EPI unit with their baby during the data collection period and who had their infants/children less than 15 months were included in the study. However, Mothers who were not able to breastfeed their baby due to any known medical problems, infants who were bottle feeders, and infants brought to the EPI unit by other attendants rather than their mother were excluded from the study.

\section{Sample size and sampling procedure}

The sample size was calculated by using single population proportion formula based on the following statistical assumptions; $P=43 \%$ (Proportion of effective BFT from the study conducted in Harar city, Harari regional state, Eastern Ethiopia 2017) [24], 95\% confidence level, and $5 \%$ margin of error. Based on this formula and after adding a $10 \%$ non-response rate the total sample size was 414 . Thus, data were collected from 414 motherinfant dyads attending the immunization unit.

A stratified simple random sampling method was employed to approach study participants from the eight public health centers and one comprehensive specialized hospital in the town. All nine health facilities were included in the study and the total sample size was allocated proportionally to each facility. To select the desired sample of mother-infant pairs among attendants of all health facilities, the average number of mothers who visited the EPI unit of each health facility for immunization within the last 3 months before the study was identified from the client registrations. On the bases of this, the expected client flow rate during the study period ( 1 month) was estimated to be 2512 . Then, the sampling interval $(\mathrm{k})$ was calculated by dividing the expected number of the mothers visiting the unit during the study period $(\mathrm{N})$ for the determined sample size $(n)$ of respondents $(2512 / 414=6)$. Finally, using a systematic random sampling technique, one in every six mother-infant pairs was selected until the required sample was met.

\section{Data collection tool and procedure}

The required data were collected using WHO B-R-E-AS-T- Feed Observation checklist and a face-to-face structured interviewer-administered questionnaire which is adapted and modified from the previous studies [17, 24]. The observational checklist was used to determine the correctness of positioning, attachment to breast, and suckling during breastfeeding. Other data concerning socio demographic profile, infant characteristics, and maternal characteristics were collected by interviewing the mother. The English version of the tool was translated to the local language (Amharic) and to see the consistency of the tool again back to the English. The pre-test was done on the twenty respondents at "Maksegnit" health center. Inter-observer variability was also checked and adjustment was made based on the results of the pre-test.

Eight diploma nurses were recruited as data collectors and two BSc nurses as supervisors from other health facilities than that included in the study. Orientation and training were given for all data collectors and supervisors for 1 day on how to collect data, and how to observe and record the positioning, attachment, and suckling using video, images, and demonstration. After obtaining informed verbal consent, concealed observation of BFT was made for $4 \mathrm{~min}$ [21] by asking the mother to put her baby to her breast. If the infant had been fed recently and refused to feed, then the mother was asked to wait when the infant would like to suckle again while filling socio demographic data.

After observation, data collectors manually recorded the mother and infant's positioning, attachment to the breast, and suckling as per the WHO B-R-E-A-S-T Feed observation form. Each criterion under the three techniques; positioning (four criteria), attachment (four criteria) and suckling (three criteria) carry 1 point and the summation of criteria under each technique was recorded on the space provided to quantify the observation.

\section{Operational definitions}

Breastfeeding technique The composite of positioning, attachment, and suckling while breastfeeding [24]:

Positioning: Physical alignment or the way a mother holds her baby.

Attachment: The way a baby takes the breast into his mouth and whether the infant has enough areola and breast tissue in the mouth.

Suckling: The action by which a baby removes milk from the breast.

Effective breastfeeding technique The achievement of the combination of at least two criteria from positioning, 
three criteria from the attachment, and two criteria from suckling while mothers' breastfeeds their infant [17, 24]. (Table 1).

Slow suckling: suckling rhythm of about one suck per second [23].

Deep suckling: the baby's cheeks shouldn't draw inward and are rounded during a suckling, evidenced by visible or audible swallowing after every one or two sucks [23].

Breast problems: are problems such as Engorgement = painful and swollen breast and when the milk doesn't flow well, Crackle = break in the skin, sometimes called a fissure, Inverted nipple $=$ a nipple which goes inward instead of sticking out, Sore nipples $=$ pain in the nipple and areola when the baby feeds.

Table 1 Criteria and grading system for positioning, attachment, and suckling among lactating mothers visiting health facilities in Gondar town, Amhara Regional State,

Northwest Ethiopia, 2020

Criteria for correct body positioning

$$
\begin{aligned}
& \text { Baby's body close to the mother's body } \\
& \text { Baby body and neck straight } \\
& \text { Baby facing toward the mother's breast } \\
& \text { The whole body supported by the mother }
\end{aligned}
$$

Criteria for grading body positioning:
None or only one out of four criteria has been
fulfilled
Any two of the four criteria has been fulfilled
Three/all the four criteria for body positioning were
fulfilled
Criteria for the correctness of attachment
More areola is seen above the baby's top lip
The Baby's mouth is wide open
Baby's lower lip turned outwards
Baby's chin touching the breast
Criteria for grading of correct attachment:

None of or only one out of four criteria has been fulfilled

Any two of the four criteria has been fulfilled

Any three or all the four criteria has been fulfilled

Criteria for the correctness of effective suckling:

\section{Slow suckling \\ Deep suckling \\ Sometimes pausing \\ Criteria for grading of effective suckling:}

None or only one of the three criteria has been achieved

Any two or all three criteria has been achieved

$\begin{array}{ll}\begin{array}{ll}\text { Grade } & \text { Score } \\ \text { Poor } & 0-1\end{array} \\ \text { Average } & 2 \\ \text { Good } & 3-4\end{array}$

Bottle feeding: Feeding an infant from a bottle whatever is in the bottle; in addition to breastfeeding (mixed feeding) [25].

Gestational age: Preterm $<37$ weeks, term 37-42 weeks.

Pacifier - is a rubber plastic, or silicone nipple given to an infant to suck upon [24].

Parity: primipara- a mother who has given birth to only one time; multipara-a mother who has given birth 2 or more times.

\section{Data processing and analysis}

After checking for completeness, data were coded and entered into Epi-Data version 4.6 software and then exported to SPSS version 20.0 for further data analysis. Descriptive statistical analyses were computed and important variables were presented by percent, frequency, tables, and figures. The outcome variable breastfeeding technique (composite of positioning, attachment, and suckling) was dichotomized and coded as "1" for effective BFT and "0" for ineffective BFT. To call effective BFT the total score of the three composite variables should be greater than or equal to seven $(\geq 7)$ and the BFT is ineffective if the score is less than seven $(<7)$. Standardized residuals were analyzed to check the presence of outliers, as well as multi-collinearity, was checked using the variance inflation factor, and variables with variance inflation factor greater than ten were removed. Model fitness was tested using the HosmerLemeshow's goodness of fit test.

To examine the association between the independent and outcome factors, initially, bi-variable logistic regression analysis was conducted. Independent variables with a $p$-value $\leq$ of 0.25 in the bi-variable logistic regression analysis were included in the multivariable logistic regression analysis to control for all possible confounders and identify the significant factors. The strength of the association between the dependent and independent variables was measured using adjusted odds ratios with 95\% CI. And if $\mathrm{OR}<1$ which means mothers not performed effective breast feeding technique whereas $\mathrm{OR}>1$ mothers applied effective breast feeding technique. The p-value of 0.05 or less was used for the final interpretation of statistical significance.

\section{Results}

Socio-demographic characteristics of the respondents

Out of a total of 414 lactating mother-infant pairs were participated in this study, of which 410(99\%) were responded. Near to $91 \%, 372(90.7 \%)$ of the respondents were urban dwellers. In this study, the mean ages of the respondents were $27.3+4.8 \mathrm{SD}$ years old. The majority of study participants 391(95.4\%) were married and twothirds $272(66.3 \%)$ of them were housewives. Regarding
Grade Score

Ineffective $0-1$

Effective 2-3 
their level of education, more than one third 153(37.3\%) of them had attended up to secondary school (Table 2).

\section{Maternal obstetric and infant characteristics}

Two hundred thirty $(56.1 \%)$ of the mothers had previous breastfeeding experience, and 231(56.3\%) of them were multiparous. The majority of 388(95\%) mothers had ANC follow-up visits during their last pregnancy. Significant number of mothers, 386(94\%) gave birth to their current baby at health facilities, however, many of the mothers 322(78.5\%) had not received counseling about BFT during their ANC follow-up. Abundant number of

Table 2 Socio-demographic characteristics of lactating mothers attending EPI in public health facilities in Gondar town, Amhara Regional State, Northwest Ethiopia $2020(n=414)$

\begin{tabular}{|c|c|c|}
\hline Variables & Frequency & Percent \\
\hline \multicolumn{3}{|l|}{ Residence } \\
\hline Urban & 372 & 90.7 \\
\hline Rural & 38 & 9.3 \\
\hline \multicolumn{3}{|l|}{ Age of mother in year } \\
\hline$<20$ & 29 & 7.1 \\
\hline $20-25$ & 130 & 31.7 \\
\hline $26-30$ & 170 & 41.4 \\
\hline$>30$ & 81 & 19.8 \\
\hline \multicolumn{3}{|l|}{ Ethnicity } \\
\hline Amhara & 352 & 85.9 \\
\hline Kimant & 38 & 9.3 \\
\hline other $^{a}$ & 20 & 4.9 \\
\hline \multicolumn{3}{|l|}{ Religion } \\
\hline Orthodox & 348 & 84.9 \\
\hline Muslim & 56 & 13.7 \\
\hline Protestant & 6 & 1.5 \\
\hline \multicolumn{3}{|l|}{ Marital status } \\
\hline Married & 391 & 95.4 \\
\hline Divorced & 17 & 4.1 \\
\hline other $^{\mathrm{b}}$ & 2 & 0.5 \\
\hline \multicolumn{3}{|l|}{ Occupation } \\
\hline housewife & 272 & 66.3 \\
\hline government employee & 73 & 17.8 \\
\hline self-employee & 44 & 10.7 \\
\hline other ${ }^{c}$ & 21 & 5.1 \\
\hline \multicolumn{3}{|l|}{ Educational status } \\
\hline has no formal education & 54 & 13.2 \\
\hline grade $1-8$ & 91 & 22.2 \\
\hline grade $9-12$ & 153 & 37.3 \\
\hline diploma and above & 112 & 27.3 \\
\hline
\end{tabular}

${ }^{\mathrm{a} O r o m o}$, Tigre, Wolayta, and Hadiya

bSingle and widowed

${ }^{\mathrm{c}} \mathrm{NGO}$ employee, daily laborer, and student participants, 387(94.4\%) had not breast related problems. Related to infant's or children's characteristics, 284(69.3\%) of them were found within the age range 0 6 months. Small number of infants, 21(5.1\%) were used bottle feeding, and $70(17.1 \%)$ were used pacifier (Table 3).

\section{Breastfeeding technique status}

The proportion of effective breastfeeding technique in the study area was [48\% (95\%; CI: 43.0-53.0\%)]. The majority, $289(70.5 \%)$ of the mother exhibits good positioning. Infant attachment was good, and suckling was effective in 241(58.8\%) and 286(69.8\%), respectively (Fig. 1).

\section{Factors associated with breastfeeding technique}

In both bivariate and multivariable logistic regression analyses, the age of the mother, parity, counseling about BFT during ANC follow-up, and immediately after delivery, as well as breast problem and bottle feeding, were significantly associated factors for BFT.

The odds of effective BFT was $70 \%$ less than $(\mathrm{AOR}=$ 0.3 ; 95\% CI: $0.11,0.83$ ) among age group 18-20 compared to age group greater than 30 years. The probability of Effective BFT was $52 \%$ less than $(\mathrm{AOR}=0.48$; 95\% CI: 0.26-0.88) among age group 26-30 years compared to age group greater than 30 years. The odds of effective BFT in primipara were $49 \%$ (AOR $=0.51$; $95 \%$ CI: 0.32 0.82 ) lower compared to multiparous mothers. Similarly, the likelihood of having effective BFT was $45 \%$ less than $[(\mathrm{AOR}=0.55,95 \% \mathrm{CI}: 0.32,0.95)]$ those mothers who have no counselling of BFT during ANC follow up, and $55 \%$ less than $(\mathrm{AOR}=0.45 ; 95 \%$ CI: $0.29,0.70)$ mothers who had no immediate post-natal counseling compared to their counterparts. Moreover, the result of this study showed that effective BFT was $78 \% \mathrm{AOR}=0.22$; $95 \% \mathrm{CI}$ : $0.07-0.68$ ) less in mothers with breast problem and $46 \%$ $(\mathrm{AOR}=0.54 ; 95 \% \mathrm{CI}: 0.30-0.97)$ less in bottle-feeders compared to their counterparts (Table 4).

\section{Discussions}

Ineffective breastfeeding technique is the leading cause of various problems related to breastfeeding and significantly affects both maternal and infants health $[26,27]$. This study attempted to examine the magnitude and factors associated with BFT among lactating mothers who visited public health facilities in Gondar town. The finding of this study showed that just less than half [48\% (95\%, CI: 43.0-53.0\%)] of mothers apply effective BFT, depicting the presence of poor breastfeeding technique. This is consistent with the reports of the studies conducted in Harar city, Ethiopia (43.4\%), Libya (48\%), Indonesia (46.7\%), and western Denmark (50\%) [17, 24, $28,29]$. 
Table 3 Maternal obstetric and infant characteristics of participants in public health facilities in Gondar town, Amhara Regional State, Northwest Ethiopia $2020(n=414)$

\begin{tabular}{|c|c|c|c|}
\hline Variables & & Frequency & Percent \\
\hline \multirow[t]{2}{*}{ Previous breastfeeding experience } & Yes & 230 & 56.1 \\
\hline & No & 180 & 43.9 \\
\hline \multirow[t]{3}{*}{ Breastfeeding experience duration in a years } & $<2$ & 94 & 22.9 \\
\hline & $2-5$ & 108 & 26.3 \\
\hline & $>5$ & 28 & 6.8 \\
\hline \multirow[t]{2}{*}{ Parity } & Primipara & 179 & 43.7 \\
\hline & Multipara & 231 & 56.3 \\
\hline \multirow[t]{2}{*}{$\mathrm{ANC}^{\mathrm{a}}$ follow up } & Yes & 388 & 94.6 \\
\hline & No & 22 & 5.4 \\
\hline \multirow[t]{2}{*}{ Counseling about breastfeeding technique } & Yes & 88 & 21.5 \\
\hline & No & 322 & 78.5 \\
\hline \multirow[t]{4}{*}{ Place of delivery } & Hospital & 282 & 68.8 \\
\hline & health center & 98 & 23.9 \\
\hline & private clinic & 6 & 1.5 \\
\hline & Home & 24 & 5.9 \\
\hline \multirow[t]{3}{*}{ Mode of delivery } & $S V D^{b}$ & 290 & 70.7 \\
\hline & Assisted delivery & 42 & 10.2 \\
\hline & $C / S^{c}$ & 78 & 19.0 \\
\hline \multirow[t]{2}{*}{ Immediate counseling about BFT } & Yes & 187 & 45.6 \\
\hline & No & 223 & 54.4 \\
\hline \multirow[t]{2}{*}{ PNC $^{d}$} & Yes & 175 & 42.7 \\
\hline & No & 235 & 57.3 \\
\hline \multirow[t]{2}{*}{ PNC visit frequency } & 1 time & 117 & 28.5 \\
\hline & 2 and above & 58 & 14.1 \\
\hline \multirow[t]{2}{*}{ Breast problem } & Yes & 23 & 5.6 \\
\hline & No & 387 & 94.4 \\
\hline \multirow[t]{4}{*}{ Sign and symptoms of a breast problem } & Crackle nipple & 3 & 0.7 \\
\hline & Sore nipple & 11 & 2.7 \\
\hline & Engorgement & 8 & 2.0 \\
\hline & Inverted nipple & 1 & .2 \\
\hline \multirow[t]{2}{*}{ Gestational age } & Preterm & 24 & 5.9 \\
\hline & Term & 386 & 94.1 \\
\hline \multirow[t]{2}{*}{ Sex of the infant } & Male & 213 & 52.0 \\
\hline & Female & 197 & 48.0 \\
\hline \multirow[t]{3}{*}{ Age of infant/child } & $0-6$ months & 284 & 69.3 \\
\hline & 7-12 months & 74 & 18.0 \\
\hline & 13-15 months & 52 & 12.7 \\
\hline \multirow[t]{2}{*}{ The baby started complementary feeding } & Yes & 126 & 30.7 \\
\hline & No & 284 & 69.3 \\
\hline \multirow[t]{2}{*}{ Feeding type } & Mixed & 7 & 1.7 \\
\hline & normal & 119 & 29.0 \\
\hline \multirow[t]{2}{*}{ The baby uses a bottle } & Yes & 70 & 17.1 \\
\hline & No & 340 & 82.9 \\
\hline
\end{tabular}


Table 3 Maternal obstetric and infant characteristics of participants in public health facilities in Gondar town, Amhara Regional State, Northwest Ethiopia 2020 ( $n=414)$ (Continued)

\begin{tabular}{llll}
\hline Variables & & Frequency & Percent \\
\hline The baby uses a pacifier & Yes & 21 & 5.1 \\
& No & 389 & 94.9 \\
\hline
\end{tabular}

antenatal care

b spontaneous vaginal delivery

'caesarian section d postnatal care

The proportion is considerably higher than the findings of the study done in the south Ari district of Ethiopia (36.5\%) [30]. This variation might be because of the difference in the composition of study participants. For instance, a fewer portion of younger mothers was participated in the current study, unlike Ari district study participants. The proportion is, however, lower than the studies conducted in Nigeria (71.3\%) and West Bengal/Kolkata in India(74\%) [31, 32]. This is probably due to the variation in the data collection method and target population. The data collection method was not direct observation in the Nigerian study, which may lead to the over-reporting of the practice. In the Bengal study, only mothers in the postnatal ward were included in the study.

Younger mothers aged $18-20$ and $20-26$ years old were 70 and $52 \%$ less likely to practice effective breastfeeding techniques respectively, compared to mothers whose ages were greater than 30 years. This indicates that young mothers are offering breastfeeding to their infants' inappropriately, which could ultimately adversely affects their health. Similar findings were reported from studies done in a teaching hospital in coastal Karnataka, India, Indonesia, and Libya $[10,17,33,34]$. This shows an increase in mothers' age rises the experience of BFT and their confidence in child handling.
The present study shows that the odds of effective BFT decrease almost by half $(49 \%)$ in primipara compared to multiparous mothers. This shows the use of BFT is poor in women giving birth for the first time. This is in line with the finding from studies in India, Australia, and Ethiopia [3, 30, 35, 36]. This could be due to a reason multiparous mothers might have frequent BFT counseling and exposure previously, which may enable them to acquire and master the skill of breastfeeding, unlike primipara.

This study also showed that counseling about BFT had a significant contribution to effective BFT. The odds of effective BFT were $45 \%$ less likely in mothers who had no counseling during antenatal care follow-up compared to those who had counseling. This finding remarks that ANC follow-up has added postpartum purposes beyond assessing pregnancy risks and giving appropriate care. Similar findings were reported from a study done in Karnataka India, Libya, Harar city, and Ari southern Ethiopia [17, 24, 30, 34]. Antenatal counseling may enhance the mother's knowledge and help them to convert this knowledge to practice as early as possible after delivery, whether they get immediate post-natal counseling or not.

Similarly, the usages of effective BFT were $55 \%$ less likely in mothers who had no immediate postnatal counseling compared to their counterparts. This suggests that

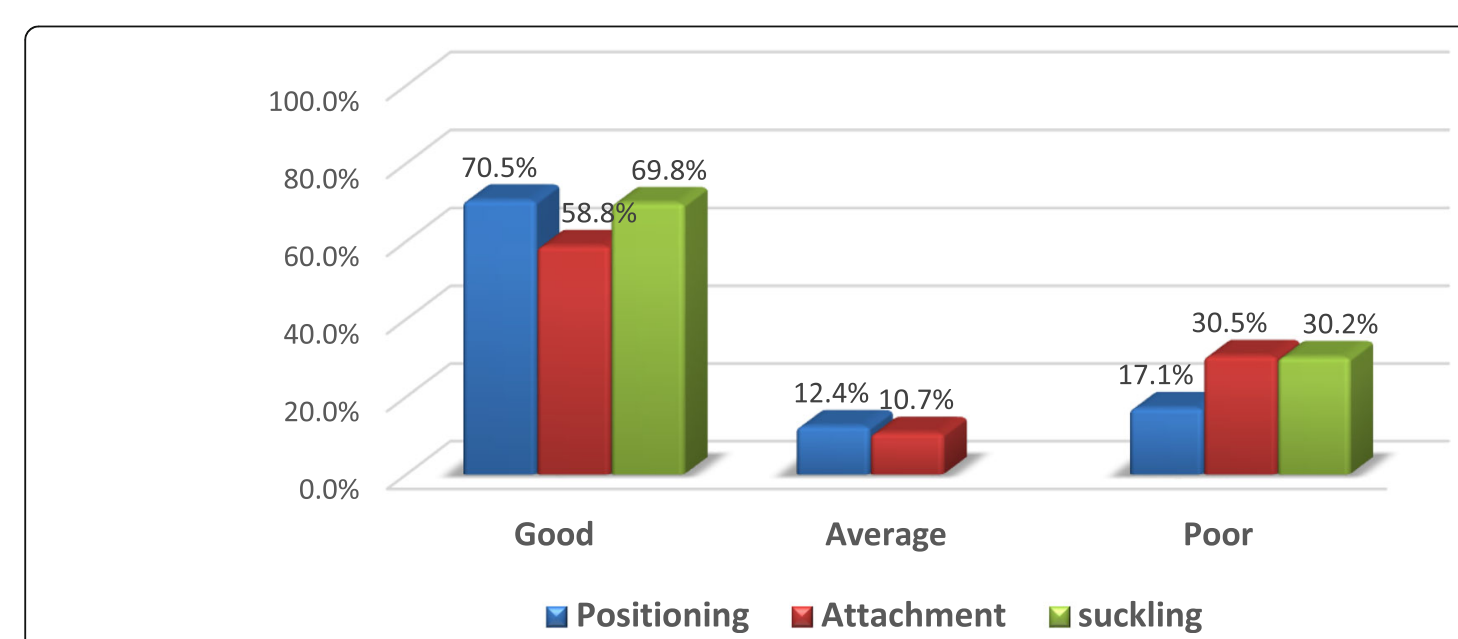

Fig. 1 Breastfeeding technique status of lactating mothers visiting public health facilities in Gondar town, Amhara Regional State, Northwest Ethiopia 2020 
Table 4 Bivariate and multivariable logistic regression analysis for breastfeeding techniques by maternal and infant factors among lactating mothers visiting Gondar town health facilities, Amhara regional state, northwest Ethiopia, 2020. $(n=414)$

\begin{tabular}{|c|c|c|c|c|c|}
\hline \multirow[t]{2}{*}{ Variables } & & \multicolumn{2}{|c|}{ Effectiveness of BFT: } & \multirow[t]{2}{*}{$\operatorname{COR}(95 \% \mathrm{CI})$} & \multirow[t]{2}{*}{ AOR $(95 \% \mathrm{Cl})$} \\
\hline & & Effective N (\%) & In-effective N (\%) & & \\
\hline \multirow[t]{4}{*}{ Age of mother } & $18-20$ & $9(31.0)$ & $20(69.0)$ & $0.21(0.08-0.53)^{*}$ & $0.30(0.11-0.83)^{* *}$ \\
\hline & $21-25$ & $53(40.8)$ & $77(59.2)$ & $0.32(0.18-0.58)^{*}$ & $0.45(0.23-0.87)^{* *}$ \\
\hline & $26-30$ & $80(47.1)$ & $90(52.9)$ & $0.42(0.24-0.73)^{*}$ & $0.48(0.26-0.88)^{* * *}$ \\
\hline & $>30$ & $55(67.9)$ & $26(32.1)$ & 1.0 & 1.0 \\
\hline \multirow[t]{2}{*}{ Marital status } & Married & 193(49.4) & 198(50.6) & 1.0 & 1.0 \\
\hline & Other & $4(21.1)$ & 15(78.9) & $0.27(0.09-0.84)^{*}$ & $0.34(0.10-1.13)$ \\
\hline \multirow[t]{2}{*}{ Parity } & primipara & 63(35.2) & $116(64.8)$ & $0.39(0.26-0.59)^{*}$ & $0.51(0.32-0.82)^{* *}$ \\
\hline & multipara & 134(58.0) & $97(42.0)$ & 1.0 & 1.0 \\
\hline \multirow[t]{2}{*}{ Counseling of BFT during ANC follow up } & Yes & $58(65.9)$ & $30(34.1)$ & 1.0 & 1.0 \\
\hline & No & 139(43.2) & 183(56.8) & $0.39(0.24-0.64)^{*}$ & $0.55(0.32-0.95)^{* *}$ \\
\hline \multirow[t]{2}{*}{ Immediate PNC counseling } & Yes & $115(61.5)$ & $72(38.5)$ & 1.0 & 1.0 \\
\hline & No & $82(36.8)$ & $141(63.2)$ & $0.36(0.24,0.54)^{* *}$ & $0.45(0.29,0.70)^{* *}$ \\
\hline \multirow[t]{2}{*}{ Breast problem } & yes & $4(17.4)$ & 19(82.6) & $0.21(0.07,0.63)^{*}$ & $0.22(0.07,0.68)^{* *}$ \\
\hline & No & 193(49.9) & 194(50.1) & 1.0 & 1.0 \\
\hline \multirow[t]{2}{*}{ Gestational age } & preterm & $8(33.3)$ & $16(66.7)$ & $0.52(0.22,1.25)$ & $0.46(0.18,1.20)$ \\
\hline & term & 189(49.0) & 197(51.0) & 1.0 & 1.0 \\
\hline \multirow[t]{2}{*}{ Bottle feeding } & yes & $26(37.1)$ & $44(62.9)$ & $0.58(0.34,0.99)^{*}$ & $0.54(0.30,0.97)^{* *}$ \\
\hline & No & $171(50.3)$ & $169(49.7)$ & 1.0 & 1.0 \\
\hline
\end{tabular}

*Bi-Variable significant ( $p$-value $<0.05$ )

** multivariable significant ( $p$-value $<0.05$ )

the immediate postnatal period is the most critical time for BFT counseling since all the mother's attention is toward her baby during this time. This findings consistent with study done in northern India, Saudi Heraa general hospital, and Harar [24, 37, 38].. This is due to the direct observation of breastfeeding by a health care provider as a routine activity and repeated demonstration of breastfeeding techniques.

Moreover, mothers who had breast problems like engorgement, mastitis, and crackle were $78 \%$ less likely to display effective BFT than those mothers without breast problems, which means the prevention of breast problems is crucial for successful breastfeeding. The same is true in the finding of the studies conducted in Libya, and Eastern and southern Ethiopia [17, 24, 30]. This could be related to the fear of pain and discomfort felt by the mother with the problem during breastfeeding. Similarly, in the present study, there was a significant association between BFT and bottle-feeding. Mothers who have bottle feeding practice were $46 \%$ less likely to demonstrate effective BFT., This is in accordance with the previous study conducted in Brazil, BFT was significantly affected by bottle-feeding [39]. This might be due to the mothers who bottle-fed their baby wouldn't frequently breastfeed their baby.

\section{Limitation of the study}

Since the main data collection method was the use of an observational checklist the study might be subjected to the Hawthorne effect, though, this effect was tried to be minimized by concealing the observation from the study participants. Lack of repeated observation of breastfeeding techniques may compromise the ascertainment of the breastfeeding technique status of the mothers.

\section{Conclusion}

In conclusion, this study revealed that the proportion of effective breast feeding technique was slightly high compared to a study done in Harar, Ethiopia. The sociodemographic variable like the age of the mothers(older age) and other maternal characteristics including multiparity, having counseling about breastfeeding technique during antenatal care follow-up, immediate postnatal counseling as well as not having breast problems and bottle feeding found to be an independent pronounced predictor of effective breastfeeding technique. Hence, special emphasis should be given to younger mothers and primipara mothers. Besides, preventing breast problems and working on increasing ANC and immediate postnatal counseling would improve BFT. 


\section{Abbreviations}

BFT: Breastfeeding Technique; EPI: Expanded Program for Immunization; FMOH: Federal Ministry of Health; IMNCI: Integrated Management of Newborn and Childhood Illness

\section{Acknowledgments}

We would like to express our deepest gratitude to the University of Gondar for its holistic support. We would also like to express our gratitude to the Gondar town health bureau, health facilities workers for their bottomless cooperation. Moreover, our special thanks go to data collectors and supervisors for their endless assistance and all study participants who took part in the study without any reluctance.

\section{Authors' contributions}

NT: Made a great contribution in designing and shaping the study methodology, ensured the appropriateness of the tool, supervised and extensively involved in the analysis, writing up, and interpretation of the data. DG: considerably involved in the proposal development process and tool modification, assisted the data analysis and interpretation. BL: conceived the idea for this study, ensured the quality of the data collection process, performed the data analysis, interpretation of data, and prepared the final manuscript for publication. All authors critically reviewed and approved the final manuscript.

\section{Authors' information}

NT (MSc, Assistant Professor): Lecturer at University of Gondar, College of Medicine and Health Sciences, School of Nursing, Department of Pediatrics and Child Health Nursing. DG(MSc, Assistant Professor in Pediatric and Child Health Nursing): Lecturer at University of Gondar, College of Medicine and Health Sciences, School of Nursing, Department of Pediatrics and Child Health Nursing. BL (MSc in Pediatric and Child Health Nursing): Lecturer at Bule Hora University, College of Health and Medical Sciences, Nursing Department.

\section{Funding}

University of Gondar, college of health and medical sciences covered the funding for this study.

\section{Availability of data and materials}

All data and materials relevant to this study are available from the corresponding author whenever required.

\section{Declarations}

\section{Ethics approval and consent to participate}

Ethical clearance was issued from the school of nursing research ethical review committee on behalf of the University of Gondar in a letter Ref. No. S/N/2012/01/2020. A formal ethical and cooperation letter was delivered to each health facility head or coordinator, then the head of the health facility permit, and directed a permission letter to the EPI unit team leader/ coordinator. Informed consent was obtained from the study participants on the right of participation or refusal from the study. Confidentiality of the information was kept for each study participant by coding the data.

\section{Consent for publication}

Not applicable.

\section{Competing interests}

The authors declare that they have no any competing interests to publication.

\section{Author details}

${ }^{1}$ Nursing Department, College of Health and Medical Sciences, Bule Hora University, Bule Hora, Ethiopia. ${ }^{2}$ Department of Pediatrics and Child Health Nursing, College of Medicine and Health Sciences, School of Nursing, University of Gondar, P.O .Box:196, Gondar, Ethiopia.
Received: 25 January 2021 Accepted: 21 September 2021

Published online: 12 October 2021

\section{References}

1. World Health Organization Handbook : IMCI integrated management of childhood illness. World Health Organization; 2005. https://apps.who.int/iris/ handle/10665/42939.

2. Prajapati AC, Chandwani H, Rana B, Sonaliya KN. A community based assessment study of positioning, attachment and suckling during breastfeeding among 0-6 months aged infants in rural area of Gandhinagar district, Gujarat, India. Int J Commun Med Public Health. 2016;3(7):1921-6. https://doi.org/10.18203/2394-6040.ijcmph20162066.

3. Degefa N, Tariku B, Bancha T, Amana G, Hajo A, Kusse Y, et al. Breast feeding practice: positioning and attachment during breast feeding among lactating mothers visiting health Facility in Areka Town, southern Ethiopia. Int J Pediatr. 2019;2019:1-6. https://doi.org/10.1155/2019/8969432.

4. Lawan UM, Amole GT, Jahum MG, Sani A. Age-appropriate feeding practices and nutritional status of infants attending child welfare clinic at a teaching Hospital in Nigeria. J Fam Community Med. 2014;21(1):6-12. https://doi. org/10.4103/2230-8229.128766.

5. UNICEF. Infant and young child feeding 2019 Available from: https://data. unicef.org/topic/nutrition/infant-and-young-child-feeding/.

6. Colchero MA, Contreras-Loya D, Lopez-Gatell H, González de Cosío T. The costs of inadequate breastfeeding of infants in Mexico. Am J Clin Nutr. 2015;101(3):579-86. https://doi.org/10.3945/ajcn.114.092775.

7. Haileamlak A. Appropriate infant and Yung child feeding. Ethiop J Health Sci. 2019;29(2):151-2. https://doi.org/10.4314/ejhs.v29i2.1.

8. Organization WH. Infant and young child feeding: model chapter for textbooks for medical students and allied health professionals. 2009.

9. Puapornpong P, Paritakul P, Suksamarnwong M, Srisuwan S, Ketsuwan S. Nipple pain incidence, the predisposing factors, the recovery period after care management, and the exclusive breastfeeding outcome. Breastfeed Med. 2017;12(3):169-73. https://doi.org/10.1089/bfm.2016.0194.

10. Rinata E, Sari PA. Breastfeeding practices positioning, attachment/latch-on and effective suckling. SEAJOM. 2017;3(2):1-6. https://doi.org/10.36749/sea jom.v3i2.6.

11. Lina $H$, Yunengsih $Y$, Solikhah S, Azidanti S. The association between breastfeeding technique and knowledge with exclusive breastfeeding. Jurnal Kedokteran dan Kesehatan Indonesia. 2016;7(5):214-8.

12. Sun $Y$, Vestergaard $M$, Christensen J, Olsen J. Breastfeeding and risk of epilepsy in childhood: a birth cohort study. J Pediatr. 2011;158(6):924-9. https://doi.org/10.1016/j.jpeds.2010.11.035.

13. Kurniadi A, Herini ES, Damayanti W. The role of exclusive breastfeeding in prevention of childhood epilepsy. Paediatrica Indonesiana. 2015;55(5):282-6. https://doi.org/10.14238/pi55.5.2015.282-6.

14. Mesfin F, Husein J, Baraki N. Exclusive breastfeeding practice and associated factors among mothers of infants aged under six months in rural kebeles of Boke district, West Hararghe Zone. Eastern Ethiopia: Haramaya University; 2018.

15. United Nations Inter-agency Group for Child Mortality Estimation (UN IGME). Child Mortality Estimates 2019 Available from: https://childmortality.org/.

16. Organization $W H$, Unicef. Baby-friendly hospital initiative: revised, updated and expanded for integrated care. 2009.

17. Goyal RC, Banginwar AS, Ziyo F, Toweir AA. Breastfeeding practices: positioning, attachment (latch-on) and effective suckling - a hospital-based study in Libya. J Fam Community Med. 2011;18(2):74-9. https://doi.org/1 0.4103/2230-8229.83372.

18. Tamiru D, Jisha H. Breastfeeding skills in Arba Minch Zuria: the positioning and attachment initiatives. Int J Nurs Midwife. 2017;9(4):46-52. https://doi. org/10.5897/IJNM2016.0237.

19. Guideline: Protecting, Promoting and Supporting Breastfeeding in Facilities Providing Maternity and Newborn Services. Geneva: World Health Organization; 2017.

20. Eidelman Al, Schanler RJ. Breastfeeding and the use of human milk. Pediatrics. 2012;129(3):e827-41. https://doi.org/10.1542/peds.2011-3552. Epub 2012 Feb8 27.

21. $\mathrm{FMOH}$. Integrated management of childhood illness federal ministry of health(IMNCI) module two. Adis Abeba; 2016. https://publications.jsi.com/ JSIInternet/Inc/Common/_download_pub.cfm?id=23271\&lid=3.

22. Government of Ethiopia FMoH. National Guideline for the Management of Acute Malnutrition. Addis Ababa: FMOH; 2019. 
23. Breastfeeding- How to interpret your baby's sucking patterns [Available from: https:/www.kidspot.com.au/baby/feeding/breastfeeding/how-tointerpret-your-babys-sucking-patterns/news-story/98cddead9fdc555bcd23 79ace5ad0faa.

24. Tiruye G, Mesfin F, Geda B, Shiferaw K. Breastfeeding technique and associated factors among breastfeeding mothers in Harar city, eastern Ethiopia. Int Breastfeed J. 2018;13(1):5. https://doi.org/10.1186/s13006-0180147-z.

25. WHO U. Infant and Young Child Feeding Counselling: An Integrated Course 2006 Available from: http://www.who.int/nutrition.

26. Lee MK, Binns C. Breastfeeding and the risk of infant illness in Asia: a review. Int J Environ Res Public Health. 2020;17(1):186.

27. KJdS S, Santana GS, TdO V, CAdST S, ERJ G, Vieira GO. Prevalence and factors associated with cracked nipples in the first month postpartum. BMC Pregnancy Childbirth. 2016;16(0):209.

28. Iflahah D. The correct breastfeeding practices in terms of age, Parity, Maternal Age, Gestation, and Birth Weight in RSUD Sidoarjo. Midwifery Siti Khodijah Academies Muhammadiyah of Sepanjang-Sidoarjo. 2012.

29. Kronborg $\mathrm{H}$, Væth $\mathrm{M}$. How are effective breastfeeding technique and pacifier use related to breastfeeding problems and breastfeeding duration? Birth. 2009;36(1):34-42. https://doi.org/10.1111/j.1523-536X.2008.00293.X.

30. Yilak G, Gebretsadik W, Tadesse H, Debalkie M, Bante A. Prevalence of ineffective breastfeeding technique and associated factors among lactating mothers attending public health facilities of south Ari district, Southern Ethiopia. PLoS One. 2020;15(2):e0228863. https://doi.org/10.1371/journal. pone.0228863.

31. Mbada CE, Olowookere AE, Faronbi JO, Oyinlola-Aromolaran FC, Faremi FA, Ogundele $\mathrm{AO}$, et al. Knowledge, attitude and techniques of breastfeeding among Nigerian mothers from a semi-urban community. BMC Res Notes. 2013;6(1):552. https://doi.org/10.1186/1756-0500-6-552.

32. Dasgupta U, Mallik S, Bhattacharyya K, Sarkar J, Bhattacharya S, Halder A. Breastfeeding practices: positioning, attachment and effective suckling-a hospital based study in West Bengal/Kolkata. Indian J Mater Child Health. 2013;15:1-11.

33. Dasgupta U, Mallik S, Bhattacharyya K, Sarkar J, Bhattacharya S, Halder A. Breastfeeding practices: positioning, attachment and effective suckling - ahospital based study in West Bengal/Kolkata. Indian J Mater Child Health. 2013;15:1-11. https://sljch.sljol.info/articles/10.4038/sljch.v46i1. 8237/.

34. Tella K, Guruvare S, Hebbar S, Adiga P, Rai L. Knowledge, attitude, and practice of techniques of breast-feeding among postnatal mothers in a coastal district of Karnataka. Int J Med Sci Public Heal. 2016;5(1):28. https:// doi.org/10.5455/ijmsph.2016.100620159.

35. Jeenamol C, Gnanadurai A, Vincent R, Xavier R. Effect of skill orientation on practice of breast feeding technique among mothers of preterm babies. Asian J Nurs Educ Res. 2016;6(4):517. https://doi.org/10.5958/2349-2996.2016. 00097.5.

36. Cantrill RM, Creedy DK, Cooke M, Dykes F. Effective suckling in relation to naked maternal-infant body contact in the first hour of life: an observation study. BMC Pregnancy Childbirth. 2014;14(1):20. https://doi.org/10.1186/14 71-2393-14-20.

37. Gupta SA, Sharma M, Ekka A, Verma N. Effect of health education on breastfeeding initiation techniques among postnatal mothers admitted in a tertiary care Centre of Raipur city, Chhattisgarh. Int I Commun Med Public Health. 2018;5(10):4340-4. https://doi.org/10.18203/2394-6040.ijcmph20183 971.

38. El-Khedr SM, Lamadah SM. Knowledge, attitude and practices of Saudi women regarding breastfeeding at Makkah al Mukkaramah. J Biol Agriculture Health Care. 2014;4:56-65.

39. Batista CLC, Ribeiro VS, Nascimento MDSB, Rodrigues VP. Association between pacifier use and bottle-feeding and unfavorable behaviors during breastfeeding. J Pediatr. 2018;94(6):596-601. https://doi.org/10.1016/j.jped.2 017.10.005.

\section{Publisher's Note}

Springer Nature remains neutral with regard to jurisdictional claims in published maps and institutional affiliations.

\section{Ready to submit your research? Choose BMC and benefit from:}

- fast, convenient online submission

- thorough peer review by experienced researchers in your field

- rapid publication on acceptance

- support for research data, including large and complex data types

- gold Open Access which fosters wider collaboration and increased citations

- maximum visibility for your research: over $100 \mathrm{M}$ website views per year

At BMC, research is always in progress.

Learn more biomedcentral.com/submissions 